九州大学学術情報リポジトリ

Kyushu University Institutional Repository

\title{
Top-down and bottom-up visual information processing of non-social stimuli in high- functioning autism spectrum disorder
}

Maekawa, Toshihiko

Department of Psychiatry, Harvard Medical School Boston VA Healthcare System

Tobimatsu, Shozo

Department of Clinical Neurophysiology, Graduate School of Medical Sciences, Kyushu University

Inada, Naoko

Department of Child and Adolescent Mental Health, National Institute of Mental Health, National Center of Neurology and Psychiatry

Oribe, Naoya

Department of Neuropsychiatry, Graduate School of Medical Sciences, Kyushu University

他

http://hdl. hand le. net/2324/25439

出版情報 : Research in Autism Spectrum Disorders. 5 (1), pp.201-209，2011-01. Elsevier バージョン:

権利関係: (C) 2011 Elsevier Inc. 
Top-down and bottom-up visual information processing of non-social stimuli in high-functioning autism spectrum disorder

Toshihiko Maekawa ${ }^{a, b, c}$, Shozo Tobimatsu ${ }^{c}$, Naoko Inada ${ }^{d}$, Naoya Oribe ${ }^{b}$, Toshiaki Onitsuka $^{\text {b }}$, Shigenobu Kanba ${ }^{\text {b }}$, Yoko Kamio ${ }^{\mathrm{d}}$

${ }^{a}$ Department of Psychiatry, Harvard Medical School Boston VA Healthcare System, Jamaica Plain VA and Brockton VA campus, United States

${ }^{b}$ Department of Neuropsychiatry, Graduate School of Medical Sciences, Kyushu University, Japan.

${ }^{c}$ Department of Clinical Neurophysiology, Graduate School of Medical Sciences, Kyushu University, Japan.

${ }^{\mathrm{d}}$ Department of Child and Adolescent Mental Health, National Institute of Mental Health, National Center of Neurology and Psychiatry, Japan.

Corresponding author: Toshihiko Maekawa, MD, $\mathrm{PhD}$

Address: Department Neuropsychiatry, Graduate School of Medical Sciences, Kyushu University 3-1-1 Maidashi, Higashi-Ku, Fukuoka 812-8582, Japan

Telephone: +81-92-642-5625

Fax: +81-92-642-5644

E-mail: t-mae@npsych.med.kyushu-u.ac.jp 


\begin{abstract}
Objective: Individuals with high functioning autism spectrum disorder (HF-ASD) often show superior performance in simple visual tasks, despite difficulties in the perception of socially important information such as facial expression. The neural basis of visual perception abnormalities associated with HF-ASD is currently unclear. We sought to elucidate the functioning of bottom-up and top-down visual information processing in HF-ASD using event-related potentials (ERPs). Methods: Eleven adults with HF-ASD and 11 age-matched normal controls (NC) participated in this study. Visual ERPs were recorded using 128-channel EEG. The P1 and P300 were recorded in response to target stimuli. Visual mismatch negativity (vMMN) potentials were obtained by subtracting responses to standard from those to deviant stimuli. Results: Behaviorally, individuals with HF-ASD showed faster target detection than NCs. However, vMMN amplitude and latency were the same between the two groups. In contrast, P1 and P300 amplitudes were significantly decreased in HF-ASD compared with NCs. In addition, P300 latency was significantly delayed in HF-ASD. Conclusions: Individuals with HF-ASD exhibit altered visual information processing. Intact bottom-up attention (vMMN) may contribute to their superior simple visual task performance in spite of abnormal low-level (P1) and top-down (P300) visual information processing.
\end{abstract}

\title{
Keywords
}

Autism spectrum disorder, mismatch negativity, P300, bottom-up attention, top-down attention, visual processing 


\section{Introduction}

Autism spectrum disorder (ASD) is a developmental neuropsychiatric disorder characterized by deficits in socialization, communication, and repetitive/stereotyped behaviors. Over the past several decades, extensive studies using various genetic, neurobiological, cognitive and behavioral approaches have sought a single explanation for the heterogeneous manifestations of ASD, but no consensus on the etiology of ASD has emerged (Happé et al., 2006). Although there are prominent symptoms of ASD within the social domain, several researchers have proposed that abnormalities also exist in basic (lower-level) sensory processing as well as attention and cortical (higher-level) processing (Dakin and Frith, 2005; Mottron and Burack, 2001; Tuchman and Rapin, 2006). Indeed, a number of studies have shown atypical performance of individuals with ASD in a wide range of perceptual tasks (e.g. for a review, Mottron et al., 2009). In terms of research findings in the visual modality, evidence emerging over the past few decades has indicated that ASD is associated with both unique abilities and unique deficits in higher-level visual processing (Dakin and Frith, 2005). For instance, individuals with ASD generally perform well on the Wechsler Intelligence Scale for Children (WISC) Block Design test (Shah and Frith, 1983, 1993), the embedded figures test (Jolliffe and Baron-Cohen, 1997), visual search (Plaisted et al., 1998), and copying impossible figures (Mottron et al., 1999). In contrast, their 
performance tends to be poor for detecting biological motion (Blake et al., 2003), integrating rapid visual motion (Gepner and Mestre, 2002), and perceiving coherent motion (Spencer et al., 2000). These findings have often been interpreted from the viewpoint of local vs. global processing (Frith, 1989; Happé, 1999; Mottron and Burack, 2001; Plaisted, 2001). One persuasive theoretical account to explain the range of abilities and deficits characterizing ASD is 'weak central coherence' (WCC). This theory proposes that the bias toward detail-focused, local processing over global processing results in a failure to extract global form/meaning (Happé and Frith, 2006). Alternatively, the concept of top-down and bottom-up attention may be related to the peculiar visual task performance of individuals with ASD. At present a conclusive explanation remains unclear due to the limited time resolution of the psychobehavioral techniques used so far.

Visual sensory information is first processed at a low level, with information flowing from the retina to the primary visual cortex (V1). The information then passes into a higher level of neural processing. It is well known that the P1 (i.e. the first positive peak from the stimulus onset) reflects the lower-level visual information processing stage (i.e. V1 or earlier; for a review, Tobimatsu and Celesia, 2006). Previous studies have suggested that lower-level visual information processing may be affected in ASD, because affected individuals exhibit a decreased and delayed P1 (Taylor et al., 
2001; Itier and Taylor, 2002, 2004; Webb et al., in press; Hoeksma et al., 2004, 2006;

Boeschoten et al., 2007; O'Conner et al., 2005). Alternatively, selective attention may be involved. Selective attention is the process whereby a subset of the input is selected preferentially for further processing, and has two major aspects: bottom-up attention and top-down attention. Bottom-up attention is elicited or driven by the properties of stimuli automatically whereas top-down attention refers to a volitional focusing of attention on a location and/or an object based on current behavioral goals (Ciaramelli et al., 2008). These streams can operate in parallel but bottom-up attention occurs more quickly than top-down attention (e.g. Treisman et al., 1992)..Event-related potentials (ERPs), which have the benefit of a very high temporal resolution (in the order of milliseconds), are an appropriate technique for recording electrophysiological signals from the scalp. ERPs allow us to temporally characterize human sensory information processing. Two specific components of the ERP, the visual mismatch negativity (vMMN) and the visual P300, are candidates for biomarkers of bottom-up and top-down attention, respectively (Maekawa et al., 2005, 2009). To the best of our knowledge, there have been no ERP studies focusing on the bottom-up and top-down attention in ASD. Therefore, the aim of this study was to characterize visual information processing in high functioning ASD (HF-ASD) individuals, to determine whether or not bottom-up and/or top-down attention is affected by the disorder. To this end, we measured early 
visual ERP components including the P1 and P300, as well as the vMMN.

\section{Methods}

\subsection{Participants}

Eleven individuals with HF-ASD (eight males and three females, aged 18-40 years, mean age 28.0), and 11 healthy controls (HCs) matched for chronological age (CA) and sex (four males and seven females, aged 20-38 years, mean age 28.9) participated in the study. The HF-ASD group included six individuals with Asperger's disorder, three individuals with autistic disorder, and three individuals with a pervasive developmental disorder not otherwise specified (PDD-NOS). The HF-ASD participants were diagnosed by a research team including a general psychiatrist experienced in the field (T.M.), an experienced child psychiatrist (Y. K.), and a licensed clinical psychologist (N. I.) according to the DSM-IV-TR criteria (APA, 2000) based on clinical interviews with participants and/or parents using semi-structured interviews validated for Japanese PDD populations (Tani et al., 2009; Kamio et al., 2006). Diagnostic agreement among the team was obtained for all participants. The NC participants (NC group) were recruited from the general public, and their NC status was confirmed by interviews. The intellectual function of HF-ASD participants was evaluated using the Japanese versions of the Wechsler Adult Intelligence Scale 
(WAIS-R or WAIS-III).

Informed consent was obtained from all participants. The experimental procedures were approved by the ethics committee of the Graduate School of Medical Sciences, Kyushu University.

\subsection{Visual stimuli and procedures}

Visual stimuli, apparatus, procedures, and EEG recordings except for the EEG machine were the same as in our earlier studies of healthy adults (Maekawa et al., 2005, 2009).

Circular black-white windmill patterns with $90 \%$ contrast were presented on a 20-inch CRT monitor, controlled using a ViSaGe graphics board (Cambridge Research Systems, UK). The visual stimulus subtended $5.8^{\circ}$ of visual angle in diameter at a viewing distance of $114 \mathrm{~cm}$. Participants were seated comfortably in a semi-dark room. The participants were instructed to focus on a story delivered binaurally through earphones while looking at the center of the monitor, and to press a button with their right thumb as soon as they recognized a target stimulus on the monitor. Between the stimulus runs, they were asked to fill out a questionnaire about the context of the story that they had heard.

Standard, deviant, and target stimuli were presented in a random order for 200 
ms on the computer monitor (Fig. 1). The inter-stimulus interval (ISI) was $800 \mathrm{~ms}$.

Stimulus probabilities were $80 \%$ (standard), 10\% (deviant) and 10\% (target).

(Fig. 1)

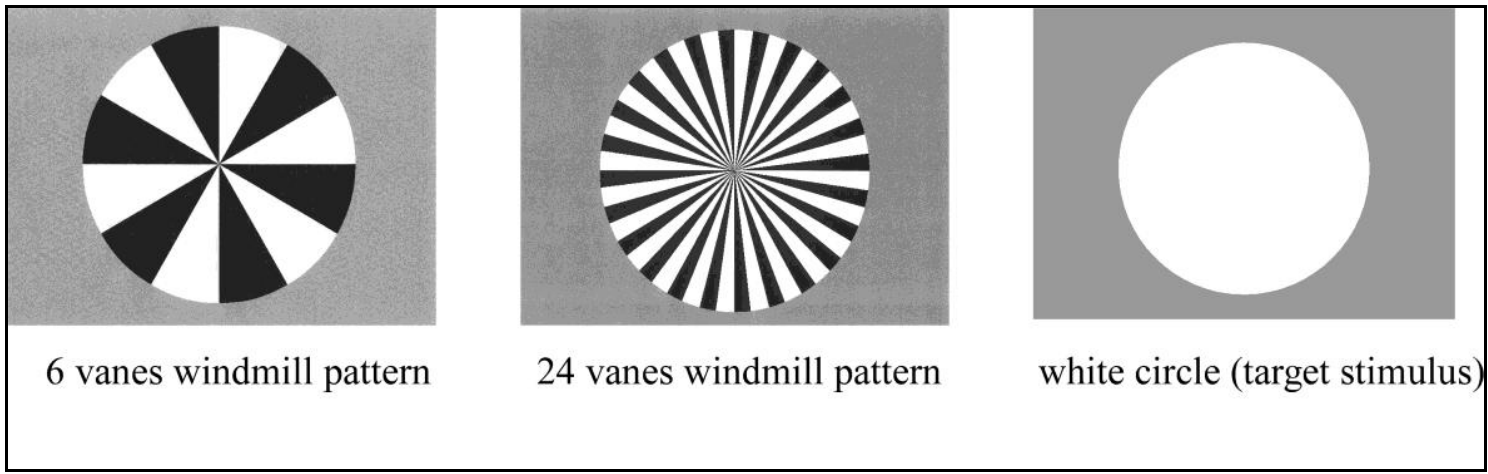

ERP recordings were composed of two sessions. One session had a windmill pattern with six vanes as the standard, 24 vanes as the deviant, and a non-patterned white circle as the target stimulus. In the other session, a six-vane windmill pattern was adopted as the deviant and a 24-vane pattern as the standard stimulus. The target stimulus was the same in both sessions.

\subsection{ERP recordings}

ERPs were recorded from 128 scalp sites referenced to $\mathrm{Cz}$, using a high-density electroencephalography (EEG) system. EEG data were analyzed using a dense array EEG workstation (Net Station, Electrical Geodesics, Inc., USA). All 128 electrodes were attached with a sensor net (Net Station, Electrical Geodesics, Inc., USA). The impedances of all electrodes were maintained below $50 \mathrm{k} \Omega$. EEG was 
continuously digitized at $500 \mathrm{~Hz}$ per channel and stored on a computer hard disk using a $0.05-200 \mathrm{~Hz}$ on-line filter. EEG data were filtered off-line with a bandpass of $0.5-30$ Hz. Digital codes synchronized to the stimulus onset were also stored. At the end of the experiments, EEG epochs of $600-\mathrm{ms}$ duration $(100 \mathrm{~ms}$ pre-stimulus, $500 \mathrm{~ms}$ post-stimulus) associated with each stimulus type were extracted from the continuous record. Epochs contaminated by electro-oculograms, blinks, or muscle artifacts exceeding an artifact rejection threshold of $\pm 70 \mu \mathrm{V}$ were discarded automatically. Artifact-free epochs were then segregated by stimulus codes and averaged for each subject. The amplitudes of the ERPs were measured relative to a 100-ms prestimulus baseline. The grand average across all subjects in each stimulus condition was also computed. To compare our findings with those of previous studies (Maekawa et al., 2005, 2009), a re-reference was applied using the average of the two electrodes beside the nose (electrodes 126 and 127). Eye movements and blinks were measured from bipolar electrodes placed above and below the eyes (right; electrodes 14 and 126, left; electrodes 21 and 127).

\subsection{Data analysis}

\subsubsection{Behavioral performance}

To characterize degree of attention, the accuracy of participants' answers to 
questions about the story was evaluated. Questionnaires consisted of 40 questions, for example "What was the name of the hero?" or "How many persons participated in the operation?" In addition, reaction time (RT) and accuracy for the target stimuli were also measured as indices of participants' task performance.

\subsubsection{ERP data}

Difference waveforms were constructed by subtracting the waveforms in response to the standard stimuli, from that to the deviants. Topographic distributions were inspected to verify that the vMMN was at its maximum at the $\mathrm{Oz}$ electrode, where the vMMN is typically largest. vMMN amplitude was calculated for each participant $150-350 \mathrm{~ms}$ from the stimulus onset. Lower-level information processing was assessed using the P1, N1, P2 and N2 components at Oz. Top-down attention was evaluated by the P300 for the target stimulus at Pz. The amplitudes of major components for each stimulus were measured relative to baseline. Peak latencies and amplitudes were then compared between HF-ASD and NC groups using student's $t$-tests.

\section{Results}

Although the behavioral performance of all participants was successfully 
measured, EEG data from two participants in each group were excluded from the ERP analyses because of excessive artifacts in their ERP recordings. Following these exclusions, there were nine participants' in each group. Although the gender ratio appeared to be quite different between the two groups (i.e. female to male ratio in HF-ASD was 7:2 and that in NC was 4:5), there were no significant between-group differences in sex ratio (Fisher's exact test, $P=0.33$ ), or CA (unpaired t-test, $P=0.29$ ).

The HF-ASD participants exhibited IQ within the normal range (mean verbal IQ, $102.8 \pm 14.3$, range 90-125 ; mean performance IQ, $108.9 \pm 13.9$, range 91-136 ; mean full scale IQ, $107.0 \pm 14.5$, range 91-134). The information subscale of the WAIS-R or WAIS-III was adopted to estimate intellectual functioning. No significant difference was found between the two groups on this subscale $(12 \pm 3.7$ vs. $13.6 \pm 1.9$, respectively).

\subsection{Performance data}

There was no significant difference in mean accuracy rate for questions related to the story context between the HF-ASD and NC groups (97.0vs. $96.9 \%$, respectively), confirming that both groups cooperated successfully and paid a high level of attention to the story. There was no significant difference in target stimulus detection accuracy between the two groups $(92.5 \pm 6.3$ vs. $92.1 \pm 4.7 \%$, respectively). 
However, the HF-ASD group showed significantly shorter RTs than the NC group (374. $2 \pm 36.6$ vs. $410.4 \pm 40.6 \mathrm{~ms}$, respectively. $P<0.05)$.

\subsection{ERPS}

Grand averaged waveforms of ERPs in response to each stimulus are shown in

Fig. 2. A positive (P1)-negative (N1)-positive (P2) deflection was elicited equally by each stimulus type, and was maximal at $\mathrm{Oz}$ (see Fig. 2A). Peak amplitudes and latencies of the $\mathrm{P} 1, \mathrm{~N} 1, \mathrm{P} 2, \mathrm{~N} 2$, and $\mathrm{P} 300$ in response to each stimulus type are summarized in Table 2. P1 amplitude in response to standard and deviant stimuli in the HF-ASD group was significantly smaller than in NCs (for standard; $t(16)=-2.47, P<$ 0.05 , for deviant stimuli; $t(16)=-2.79, P=0.013$ ). However, there was no significant difference in P1 amplitude for target stimulus between the two groups. There was also no statistical difference in P1 latency for each stimulus type between the two groups (see Table 1, Fig. 2A). There were no significant differences between the groups in the latencies and amplitudes of the N1 and P2. The mean peak amplitude of the P300 in the HF-ASD group were significantly smaller than that of NC group $(t(16)=-2.73, P$ $=0.015)$. In addition, the mean peak latency of the P300 in HF-ASD group was significantly prolonged compared with that of the NC group $(t(16)=2.91, P=0.010)$ (Fig. 2B). 
Although vMMN was clearly exhibited at the occipital and posteriotemporal electrodes in both groups, there was no statistical difference in either the peak latency or mean amplitude between groups (Table 1, Figs. $2 \mathrm{C}$ and 3).

(Figs. 2)

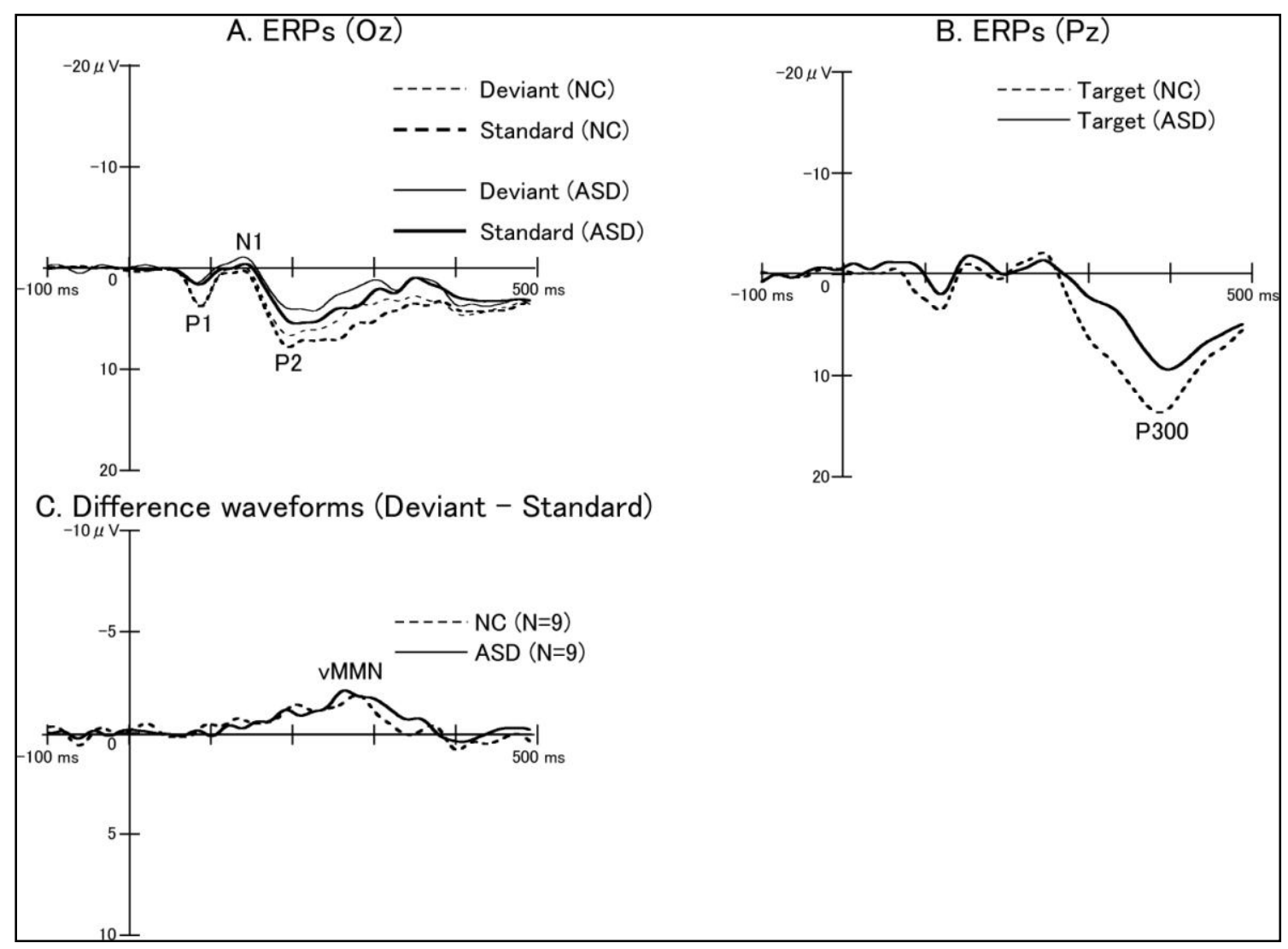




\section{(Table 1)}

Mean latencies (ms) and amplitudes $(\mu \mathrm{V})$ of the P1, N1, P2, N2, P300 in NC and HF-ASD groups.

\begin{tabular}{llcccc}
\hline \multirow{2}{*}{ Stimuli } & ERP peaks & \multicolumn{2}{c}{ Latency $(\mathrm{SD})$} & \multicolumn{2}{c}{ Amplitude (SD) } \\
\cline { 3 - 6 } & & NC & ASD & NC & ASD \\
\hline Standard & P1 & $96.0(11.9)$ & $94.4(12.8)$ & $5.7(2.8)$ & $2.9(1.8)^{*}$ \\
& N1 & $140.2(15.2)$ & $137.6(22.1)$ & $-1.6(3.7)$ & $-2.6(5.0)$ \\
& P2 & $224.9(18.3)$ & $218.4(29.0)$ & $8.5(4.0)$ & $7.5(4.1)$ \\
Deviant & P1 & $97.1(12.5)$ & $95.1(16.8)$ & $6.1(2.7)$ & $3.0(1.9)^{*}$ \\
& N1 & $141.3(16.9)$ & $135.3(26.0)$ & $-2.2(2.8)$ & $-2.5(4.9)$ \\
& P2 & $224.7(16.2)$ & $205.3(21.9)$ & $7.7(3.9)$ & $7.3(5.2)$ \\
Target & N2 & $293.1(18.8)$ & $287.8(33.7)$ & $1.9(2.4)$ & $-0.1(4.2)$ \\
& P1 & $118.4(5.6)$ & $121.8(5.8)$ & $8.5(4.4)$ & $6.3(3.4)$ \\
& N1 & $162.5(10.6)$ & $167.3(13.1)$ & $-1.0(2.4)$ & $-3.0(4.9)$ \\
& P2 & $191.0(11.5)$ & $200.0(8.0)$ & $1.6(1.4)$ & $0.8(4.7)$ \\
& P300 & $392.0(11.9)$ & $412.4(17.4)^{*}$ & $14.3(1.9)$ & $10.2(4.1)^{*}$ \\
Difference & vMMN & $274.2(27.9)$ & $268.7(28.1)$ & $-2.4(0.8)$ & $-2.2(1.4)$ \\
(Deviant-Standard) & & & & & \\
\hline *P <0.05) & & & & & \\
\hline
\end{tabular}


(Figs. 3)

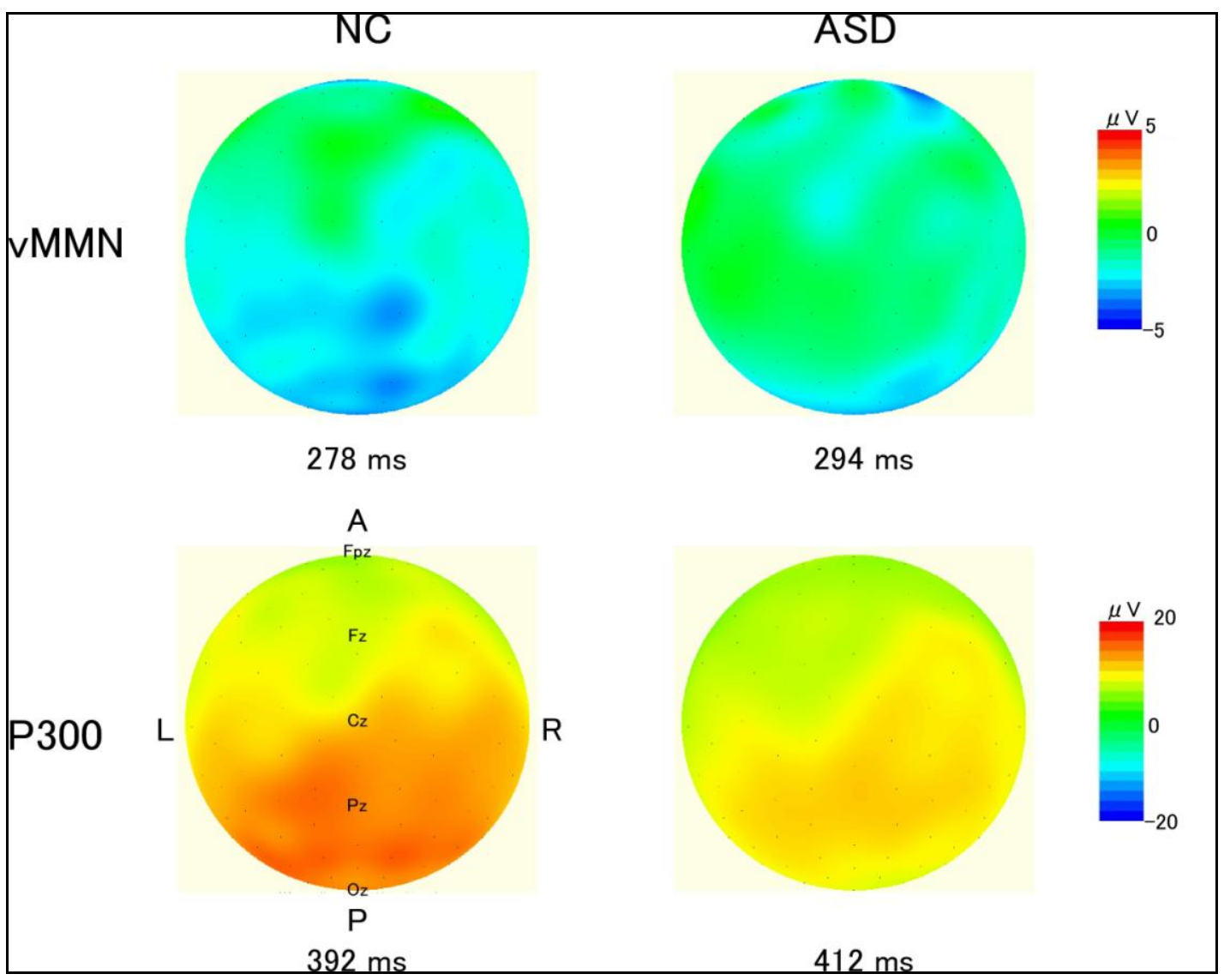

\section{Discussion}

The major differences we found between the HF-ASD group and the NC group are summarized as follows. In HF-ASD individuals, 1) behavioral target detection was significantly faster, 2$)$ the P1 response $(80-120 \mathrm{~ms})$ to standard and deviant stimuli was significantly smaller, 3) the P300 latency (300-500 ms) was significantly prolonged and its amplitude was decreased and 4) both the mean amplitude and latency of vMMN (150-300 ms) were within the normal range. These findings suggest that individuals with HF-ASD exhibit differences in perceptual 
integration, with a unique electrophysiological processing pattern. Namely, this group exhibits abnormal lower-level (P1) and top-down attentive processing (P300) while bottom-up processing (vMMN) appears to be intact. In the following section, we will discuss the pattern of unusual electrophysiological activity we observed in HF-ASD individuals in terms of bottom-up and top-down attention.

\subsection{Abnormal lower visual level processing}

The reduced P1 amplitude we observed in the HF-ASD group in our study suggests abnormalities in lower-level visual processing, in accord with previous reports (Taylor et al., 2001; Itier and Taylor, 2002, 2004; Webb et al., in press; Hoeksma et al., 2004, 2006; Boeschoten et al., 2007; O'Conner et al., 2005). Boeschoten et al. (2007) focused on the effect of spatial frequency (SF). They examined early visual sensory processing in HF-ASD children using two types of horizontal grating stimuli. They found that P1 responses evoked by both low ( 0.75 cycles/deg or four bars) and high SF (6 cycles/deg or 32 bars) gratings were significantly decreased in the HF-ASD group compared with control children. The authors suggested that atypical social perception and recognition (including deficits in face processing) in ASD may be caused by more fundamental lower-level visual processes. In accord with this report, we also found that HF-ASD individuals exhibited a significantly smaller P1 in response to windmill 
patterns of both low (6-vane) and high (24-vane) SF, but not in response to unpatterned stimuli. Therefore, our findings are consistent with the results of Boeschoten et al. (2007), which suggested that abnormal lower level visual information processing was also exhibited by HF-ASD adolescents and adults.

Our interpretation is in accord with previous findings showing that hierarchical face processing is differentially influenced by the removal of high and low SF content, (Badcock et al., 1990; LaGasse, 1993; Boeschoten et al., 2005; Goffaux et al., 2003, 2005; Ruiz-Soler and Beltran, 2006). Thus, the local visual processing biases often found in ASD (e.g., Dankin and Frith, 2005; Happé and Frith, 2006; Mottron et al., 2006; Behrmann et al., 2006b) may be related to abnormal early processing of SF. Furthermore, abnormal processing of low SF stimuli was also found in our study. Namely, we found that HF-ASD individuals exhibited decreased P1 amplitude in response to 6-vane windmill patterns. This could be related to the abnormal face and emotion recognition often reported in ASD (Braverman et al., 1989; Hobson and Lee, 1989; Baron-Cohen et al., 1999; Critchley et al., 2000; Wang et al., 2004; Dawson et al., 2004), because low SF information is important for both face recognition and emotion perception (Tanskanen et al., 2005; Vuilleumier et al., 2003; Pourtois et al., 2005). 


\subsection{Distinct electrophysiological features of $H F-A S D$}

To our knowledge, this is the first report of vMMN in an HF-ASD group. However, there have been several previous MMN studies in the auditory modality (Ceponiene et al., 2002, 2003; Dunn et al., 2008; Kuhl et al., 2005; Lepistö et al., 2005, 2006, 2008, 2009). Kuhl et al. (2005) found that the children with ASD showed a normal MMN to changes in non-speech sounds, but showed no MMN in response to changes in speech syllables. In general, the majority of autistic children preferred to listen to non-speech sounds, thus demonstrating an association between cortical processing of language and behavior (Kuhl et al., 2005). In the current study we found that vMMN in response to a non-social stimulus (a windmill pattern) was preserved. This finding suggests that the preattentive visual information processing involved in detecting subtle changes in the visual environment is intact in HF-ASD.

On the other hand, the P300 in individuals with HF-ASD was significantly smaller than that of NCs in the present study. There have been a small number of studies examining the visual P300 in ASD (see for a review, Jaste and Nelson, 2009). In addition, there have been several reports showing a smaller auditory P300 in ASD, despite normal behavioral performance (e.g. Ciesielski et al., 1990; Lincoln et al., 1993). These findings for auditory tasks imply that individuals with ASD have altered cortical processing that may interfere specifically with speech sounds but not pitch 
sounds. In light of these previous findings, we expected that individuals with HF-ASD would show intact vMMN and smaller a P300 in response to a non-social stimulus such as a visual windmill pattern. Several previous studies demonstrated a smaller visual P300 in children with ASD (Gomarus et al., 2009; Gunji et al., 2008; Hoeksma et al., 2004, 2006; Kemner et al., 1999; Verbaten et al., 1991; Pitchard et al., 1987). However, there the P300 findings in adults with HF-ASD have not been consistent. Courchesne et al. (1985a, b, 1989) and Hoeksma et al. $(2004,2006)$ reported a normal P300 in HF-ASD adults, while Townsend et al. (2001) found a significantly reduced P300. In addition, Hoeksma et al. (2006) found smaller P300s in response to a rectangle discrimination task in children with HF-ASD, but a normal P300 in adults with HF-ASD in the same task. These findings suggest that an abnormal P300 in children with ASD may be accompanied by abnormal selective attention, but that normalization of P300 may occur by adulthood. Thus, Hoeksma et al. (2006) interpreted their results as showing that the P300 may be an index of a compensatory process. In the present study, the P300 was significantly decreased and delayed in an HF-ASD group, in direct contrast to the findings of Hoeksma et al. (2006). It is possible that windmill pattern stimuli are more sensitive in the detection of altered visual functioning than other visual stimuli such as the rectangle used in the earlier study. 


\subsection{Bottom-up attention may compensate top-down processing}

Although a number of neuropsychological studies have investigated the neural mechanisms of both bottom-up and top-down attention, it is currently unclear whether aspects of these mechanisms are affected in HF-ASD. Our vMMN results suggest that bottom-up attention is relatively preserved in this condition, while the abnormal P300 we observed indicates that top-down attentional processing is impaired (Maekawa et al., 2005). Interestingly, individuals with HF-ASD showed faster behavioral target detection than NCs. Taking behavioral and neurophysiological findings into account, we assume that preserved bottom-up attention could cause faster target detection in our participants. There are several lines of evidence for atypical visual information processing in ASD from both neurophysiological and neuroimaging studies (see Jaste and Nelson, 2009 for a review; Müller, 2008). Superior visual performance has been more commonly observed in ASD than in other developmental cognitive disorders (see Mottron et al., 2009 for a review). Although several hypotheses (including WCC theory; Frith, 1989) have been proposed to explain this discrepancy, it remains unclear why autism is associated with superior visual task performance. Our findings may indicate that adolescents and adults with HF-ASD may exhibit involuntary or automatic processing in vMMN tasks. This idea provides a new hypothesis regarding altered visual information processing underlying the visual task performance 
advantage found in HF-ASD.

\subsection{Methodological reservations}

Although the difference in the gender ratio between groups was not statistically significant, a possible effect of the trend towards a difference should still be considered. A number of studies have demonstrated mixed gender effects on visual and auditory oddball ERPs. Lower amplitudes in males and shorter latencies in females of early VEP components including the N50, P100, N100 and N200 have been previously reported (Ehlers et al., 2001; Mitchell et al., 1987). Hoffman and Polich (1999) found that females exhibited a larger P300 component than males. However, other studies contradicted this finding, showing no significant gender difference in visual P300 (e.g. Steffensen et al., 2008; Rozenkrants and Polich, 2008). Thus, gender was unlikely to have significantly affected the results of the present study.

\section{Conclusion}

The present study is the first report focusing on bottom-up and top-down attention in HF-ASD using vMMN and the P300. Our results suggested that bottom-up involuntary attention is unaffected in HF-ASD, while lower level and top-down visual information processing are impaired in the condition. 


\section{Acknowledgment}

This study was supported in part by grants from the Research Institute of

Science and Technology for Society, Japan (RISTEX), the Naito Foundation and the Sankyo Foundation of Life Science. 


\section{References}

American Psychiatric Association. (2000). Diagnostic and Statistical Manual of Mental Disorders. 4th edition text revised (DSM-IV-TR). Washington, DC: American Psychiatric Association.

Badcock, J. C., Whitworth F. A., Badcock, D. R., \& Lovegrove, W. J. (1990). Low-frequency filtering and the processing of local-global stimuli. Perception, 19, 617-629.

Baron-Cohen, S., Ring, H. A., Wheelwright, S., Bullmore, E. T., Brammer, M. J., Simmons, A., et al. (1999). Social intelligence in the normal and autistic brain: an fMRI study. European Journal of Neurosciences, 11, 1891-1898.

Behrmann, M., Thomas, C., \& Humphreys. (2006). Seeing it differently: visual processing in autism. Trends in Cognitive Sciences, 10, 258-264.

Blake, R., Turner, L. M., Smoski, M. J., Pozdol, S. L., \& Stone, W. L. (2003). Visual recognition of biological motion is impaired in children with autism. Psychological Science, 14, 151-157.

Boeschoten, M. A., Kenemans, J. L., Engeland, H., \& Kemner, C. (2007). Abnormal spatial frequency processing in high-functioning children with pervasive developmental disorder (PDD). Clinical Neurophysiology, 118, 2076-2088.

Boeschoten, M. A., Kemner, C., Kenemans, J. L., \& van Engeland, H. (2005). The 
relationship between local and global processing and the processing of high and low spatial frequencies studied by event-related potentials and source modeling. Cognitive Brain Research, 24, 228-236.

Braverman, M., Fein, D., Lucci, D., \& Waterhouse L. (1989). Affect comprehension in children with pervasive developmental disorders. Journal of Autism and Developmental Disorders, 19, 301-319.

Ceponiene, R., Lepistö, T., Shestakova, A., Vanhala, R., Alku, P., Nä ä tä nen, R., et al. (2003). Speech-sound-selective auditory impairment in children with autism: They can perceive but do not attend. Proceedings of the National Academy of Sciences of the United States of America, 100, 5567-5572.

Ceponiene, R., Rinne, T., \& Nä ä tä nen, R. (2002). Maturation of cortical sound processing as indexed by event-related potentials. Clinical Neurophysiology, 113, 870-882.

Ciaramelli, E., Grady, C. L., \& Moscovitch, M. (2008). Top-down and bottom-up attention to memory: A hypothesis (AtoM) on the role of the posterior parietal cortex in memory retrieval. Neuropsychologia, 46, 1828-1851.

Ciesielski, K. T., Courchensne, E., \& Elmasian, R. (1990). Effects of focused selective attention tasks on event-related potentials in autistic and normal individuals. Electroencephalography and Clinical Neurophysiology, 75, 207-220. 
Courchesne, E., Couchesne, R. Y., Hicks, G., \& Lincoln, A., J. (1985a). Functioning of the brain-stem auditory pathway in non-retarded autistic individuals. Electroencephalography and Clinical Neurophysiology, 61, 491-501.

Courchesne, E., Lincoln, A. J., Kilman, B. A., \& Galambos, R. (1985b). Event-related brain potential correlates of the processing of novel visual and auditory information in autism. Journal of Autism and Developmental Disorders, 15, 55-76.

Courchesne, E., Lincoln, A. J., Yeung-Courchesne, R., Elmasian, R., \& Grillon, C. (1989). Pathophysiologic findings in nonretarded autism and receptive developmental language disorder. Journal of Autism and Developmental Disorders, $19,1-17$.

Critchley, H. D., Daly, E. M., Bullmore, E. T., Williams, S. C., van Amelsvoort, T., Robertson, D. M., et al. (2000). The functional neuroanatomy of social behavior: changes in cerebral blood flow when people with autistic disorder process facial expressions. Brain, 123, 2203-2212.

Dankin, S., \& Frith, U. (2005). Vagaries of visual perception in autism. Neuron, 48, 497-507.

Dawson, G., Webb, S. J., Garver, L., Panagiotides, H., \& McPartland, J. (2004). Young children with autism show atypical brain responses to fearful versus neutral facial expressions of emotion. Developmental science, 7, 340-359. 
Dunn, M. A., Gomes, H., \& Gravel, J. (2008). Mismatch negativity in children with autism and typical development. Journal of Autism and Developmental Disorders, $38,52-71$.

Ehlers, C. L., Wall, T. L., Garcia-Andrade, C., \& Philips, E. (2001). Auditory P3 findings in mission Indian youth. Journal of Studies on Alcohol. 62, 562-570.

Frith, U. (1989). Autism: explaining the enigma. Oxford, UK: Basil Blackwell.

Frith, U. (2004). Confusions and controversies about Asperger syndrome. Journal of Child Psychology and Psychiatry, 45, 672-686.

Gepner, B., \& Mastre, DR. (2002). Brief report: postural reactivity to fast visual motion differentiates autistic from children with asperger syndrome. (2002). Journal of Autism and Developmental Disorders, 32, 231-238.

Goffax, V., Gauthier, I., \& Rossion, B. (2003). Spatial scale contribution to early visual differences between face and object processing. Cognitive Brain Research, 16, 416-424.

Goffax, V., Hault, B., Michel, C., Vuong, Q. C., \& Rossion, B. (2005). The respective role of low and high spatial frequencies in supporting configural and featural processing of faces. Perception, 34, 77-84.

Gomarus, H. K., Wijers, A. A., Minderaa, R. B., \& Althaus, M. (2009). ERP correlates of selective attention and working memory capacities in children with ADHD 
and/or PDD-NOS. Clinical Neurophysiology, 120, 60-72.

Gunji, A., Inagaki, M., Inoue, Y., Takeshima, Y., \& Kaga, M. (2009). Event-related potentials of self-face recognition in children with pervasive developmental disorders. Brain and Development, 31, 139-147.

Happé, F., \& Frith, U. (2006). The weak coherence account: detail-focused cognitive style in autism spectrum disorders. Journal of Autism and Developmental Disorders, 36, 5-25.

Happé, F. (1999). Autism: cognitive deficit or cognitive style? Trends in Cognitive Sciences, 3, 216-222.

Hobson, R. P., \& Lee, A. (1989). Emotion-related and abstract concepts in autistic people: evidence from the British Picture Vocabulary Scale. Journal of Autism and Developmental Disorders, 19, 601-623.

Hoeksma, M. R., Kemner, C., Verbaten, M. N., \& van Engeland, H. (2004). Processing capacity in children and adolescents with pervasive developmental disorders. Journal of Autism and Developmental Disorders, 34, 341-354.

Hoeksma, M. R., Kemner, C., Kenemans, J. L., \& van Engeland, H. (2006). Abnormal selective Attention normalizes P3 amplitudes in PDD. Journal of Autism and Developmental Disorders, 36, 643-654.

Hoffman, L. D., \& Polich, J. (1999). P300, handedness, and corpus callosal size: 
Gender, modality, and task. International Journal of Psychophysiology, 3, 163-174.

Itier, R. J., \& Taylor, M. J. (2002). Inversion and contrast polarity reversal affect both encoding and recognition processes of unfamiliar faces: a repetition study using ERPs. NeuroImage, 15, 353-372.

Itier, R. J., \& Taylor, M. J. (2004).N170 or N1? Spatiotemporal differences between object and face processing using ERPs. Cerebral Cortex, 14, 132-142.

Jeste, S. S., \& Nelson, C. A. (2009). Event related potentials in the understanding of autism spectrum disorders: An analytical review. Journal of Autism and Developmental Disorders, 39, 495-510.

Jolliffe, T., \& Baron-Cohen, S. (1997). Are people with autism and Asperger syndrome faster than normal on the Embedded Figures Test? Jouranl of Child Psychology and Psychiatry, 38, 527-534.

Kamio, Y., Yukihiro, R., Adachi, J., Ichikawa, H., Inoue, M., Uchiyama, T., et al. (2006). Reliability and validity of the pervasive developmental disorder (PDD) autism society Japan rating scale (PARS): A behavior checklist for adolescent and adults with PDDs. Clinical Psychiatry (Seishin Igaku), 48, 495-505 (in Japanese).

Kemner, C., van der Gaag, R. J., Verbaten, M., \& van Engeland, H. (1999). ERP difference among subtypes of pervasive developmental disorders. Biological 
Psychiatry, 46, 781-789.

Kuhl, P. K., Coffey-Corina, S., Padden, D., \& Dawson, G. (2005). Links between social and linguistic processing of speech in preschool children with autism: Behavior and electrophysiological measures. Developmental Science, 8, F1-F12.

LaGasse, L. L. (1993). Effects of good form and spatial frequency on global precedence. Perception and Psychophysics, 53, 89-105.

Lepistö, T., Kujala, T., Vanhara, R., Alku, P., Huotilainen, M., \& Nä ä tä nen, R. (2005). The discrimination of and orienting to speech and non-speech sounds in children with autism. Brain Research, 1066, 147-157.

Lepistö, T., Silokallio, S., Nieminen,-von Wendt, T., Alku, P., Nä ä tä nen, R., \& Kujala, T. (2006). Auditory perception and attention as reflected by the brain event-related potentials in children with Asperger syndrome. Clinical Neurophysiology, 117, 2161-2171.

Lepistö, T., Kujala, T., Vanhala, R., Alku, P., Huotilainen, M., Nä ä tä nen, R. et al. (2008). The perception of invariant speech features in children with autism. Biological Psychology, 77, 25-31.

Lepistö, T., Kuitunen, A., Sussman, E., Saalasti, S., Jansson-Verkasalo, E., Wendt, T. N., \& Kujala, T. (2009). Auditory stream segregate in children with Asperger syndrome. Biological Psychology, 82, 301-307. 
Lincoln, A. J., Courchesne, E., Harms, L., \& Allen, M. (1993). Contextual probability evaluation in autistic, receptive developmental language disorder, and control children: Event-related brain potential evidence. Journal of Autism and Developmental Disorders, 23, 37-58.

Maekawa, T., Goto, Y., Kinukawa, N., Taniwaki, T., Kanba, S., \& Tobimatsu, S. (2005). Functional characterization of mismatch negativity to a visual stimulus. Clinical Neurophysiology, 116, 2392-2402.

Maekawa, T., Tobimatsu, S., Ogata, K., Onitsuka, T., \& Kanba, S. (2009). Preattentive visual change detection as reflected by mismatch negativity (MMN)—Evidence for a memory-based process. Neuroscience Research, 65, 107-112.

Mitchell, K. W., Howe, J. W., \& Spencer, S. R. (1987). Visual evoked potentials in the older population: Age and gender effects. Clinical Physics and Physiological Measurement, 8, 317-324.

Mottron, L., Burack, J. A., Stauder, J. E., \& Robaey, P. (1999). Perceptual processing among high-functioning persons with autism. Journal of Child Psychology and Psychiatry, and allied disciplines, 40, 203-211.

Mottron, L., \& Burack, J. A. (2001). Enhanced perceptual functioning in the development of autism. In Burack JA, Chaman T, Yirmiya N, Zelazo PR (Eds). Developmental psychopathology vol.1 (pp. 357-391). New York: Wiley. 
Mottron, L., Dawson, M., Soulières, I., Hubert, B., \& Burack, J. (2006). Enhanced perceptual functioning in autism: An update, and eight principles of autistic functioning. Journal of Autism and Developmental Disorders, 36, 27-43.

Mottron, L., Dawson, M., \& Soulières, I. (2009). Enhanced perception in savant syndrome: patterns, structure and creativity. Philosophical Transactions the Royal Society B, 364, 1385-1391.

Müller, R. A. (2008). From loci to network and back again: Anomalies in the study in autism. Annals of the New York Academy of Sciences, 1145, 300-315.

O’Conner, K., Hamm, J. P., \& Krik, I. J. (2005). The neurophysiological correlates of face processing in adults and children with Asperger's syndrome. Brain and Cognition, 59, 82-95.

Pitchard, W. S., Raz, N., \& August, G. J. (1987). Visual augmenting/reducing and P300 in autistic children. Journal of Autism and Developmental Disorders, 17, 231-242.

Plaisted, K., O’Riordan, M., \& Baron-Cohen, S. (1998). Enhanced visual search for a conjunctive target in autism: A research note. Journal of Child Psychology and Psychiatry Allied Disciplines, 39, 777-783.

Plaisted, K. (2001). Reduced generalization in autism: An alternative to weak central coherence. In J. A. Bruck, T. Charman, N. Yirmiya, \& P. R. Zerazo (Eds.), The development of autism: Perspectives from theory and research (pp. 149-169). 
Hillsdale, NJ: Erlbaum.

Pourtois, G., Dan, E. S., Grandjean, D., Sander, D., \& Vuilleumier, P. (2005). Enhanced extrastriate visual response to bandpass spatial frequency filtered fearful faces: time course and topographic evoked-potentials mapping. Human Brain Mapping, 26, 65-79.

Rozenkrants, B., \& Polich, J. (2008). Affective ERP processing in a visual oddball task: Arousal, valence, and gender. Clinical Neurophysiology, 119, 2260-2265.

Ruitz-Solar, M., \& Beltran, F. S. (2006). Face perception: an integrative review of the role of spatial frequencies. Psychological Research, 70, 273-292.

Shah, A., \& Frith, U. (1983). A islet of ability in autistic children: A research note. Journal of Child Psychology and Psychiatry Allied Disciplines, 24, 613-620.

Shah, A., \& Frith, U. (1993). Why do autistic individuals show superior task performance on the block design task? Journal of child psychology and psychiatry, and allied disciplines, 34, 1351-1364.

Spencer, J., O’Brien, J., Riggs, K., Baraddick, O., Atkinson, J., \& Wattam-Bell, J. (2000). Motion processing in autism: Evidence for a dorsal stream deficiency. Neuroreport, 11, 2765-2767.

Steffensen, S. C., Ohrans, A. J., Shipp, D. N., Hales, K., Stobbs, S. H., \& Fleming, D. E. (2008) Gender-selective effects of the P300 and N400 components of the visual 
evoked potential. Vision Research, 48, 917-925.

Tani, I., Yukihiro, R., \& Tsujii, M. (2009). Reliability and validity of the pervasive developmental disorder (PDD) -Autism Society Japan Rating Scale (PARS). Proceedings of Asia Pacific Autism Conference, 31.

Tanskanen, T., Nä ä tä nen, R., Montez, T., Pä ä llysaho, J., \& Hari, R. (2005). Face recognition and cortical responses show similar sensitivity to noise spatial frequency and orientation. Cerebral Cortex, 15, 526-534.

Taylor, M., Edmonds, G., McCarthy, G., \& Allison, T. (2001). Eyes first! Eye processing develops before face processing in children. Neuroreport, 12, 1671-1676.

Tobimatsu, S., \& Celesia, G. G. (2006). Studies of human pathophysiology with visual evoked potentials. Clinical Neurophysiology, 117, 1414-1433.

Tuchman, R., \& Rapin, I. (2006). Autism: A Neurological Disorder of Early Brain Development. International Review of Child Neurology Series, Mac Keith Press: London, England.

Townsend, J., Westerfield, M., Leaver, E., Makeig, S., Jung, T., Pierce, K., \& Courchesne, E. (2001). Event-related brain response abnormalities in autism: Evidence for impaired cerebello-frontal spatial attention networks. Brain Research. Cognitive Brain Research, 11, 127-145. 
Treisman, A., Vieira, A., \& Hayes, A. (1992). Automatically and preattentive processing. American Journal of Psychology, 105, 341-362.

Verbaten, M. N., Roelofs, J. W., van Engeland, H., Kenemans, J. K., \& Slangen, J. L. (1991). Abnormal visual event-related potentials of autistics children. Journal of Autism and Developmental Disorders, 21, 449-470.

Vuilleumier, P., Armony, J. L., Driver, J., \& Dolan, R. J. (2003). Distinct spatial frequency sensitivities for processing faces and emotional expressions. Nature Neuroscience, 6, 624-631.

Wang, A. T., Dapretto, M., Hariri, A. R., Sigman, M., \& Bookheimer, S. Y. (2004). Neural correlates of facial affect processing in children and adolescents with autism spectrum disorder. Journal of the American Academy of Child and Adolescent Psychiatry, 43, 481-490.

Webb, S. J., Merkle, K., Murias, M., Richards, T., Aylward, E., \& Dawson, G. ERP response differentiate inverted but not upright face processing in adults with ASD. Social Cognitive and Affective Neuroscience, in press. 


\section{Figure legends}

Fig. 1. Three stimulus types used in the present study; six-vane circular black-white windmill pattern stimulus (A), 24-vane stimulus (B) and unpatterned white circle stimulus (C). The two windmill pattern stimuli were adopted as standard or deviant stimuli (their probabilities were changed between sessions each other) and the white circle was always used as the target stimulus. Probabilities of standard, deviant and target stimuli were 8:1:1, respectively.

Fig. 2. Grand averaged waveforms of ERPs in each group. (A) Waveforms for standard stimuli (NC; thick dotted line, ASD; thick solid line) and for deviant stimuli (NC; thin dot line, ASD; thin solid line) at Oz. (B) Waveforms for target stimuli at $\mathrm{Pz}$ (NC; dotted line, ASD; solid line). While P300 latencies did not show any significant differences between the two groups, P300 amplitudes in ASD were significantly smaller than those of the NC group $(P<0.05)$. (C) Difference waveforms from responses to standard stimuli relative to responses to deviant stimuli at Oz. (NC; dotted line, ASD; solid line). There were no statistically significant differences in the mean peak latency and amplitude of vMMN between the two groups. 
Fig. 3. Topographical maps of the vMMN $(\mathrm{Oz})$ and $\mathrm{P} 300(\mathrm{Pz})$ in each group. Upper panel shows the topography of difference activity from standard to deviant stimuli of each group at vMMN peak latency. Although there was no statistically significant difference in the mean amplitude of the vMMN between the two groups, the amplitude gradient of the NC group appears to be steeper than in the ASD group. Lower panel shows the amplitude gradient of topography of response for target stimuli in each group at the P300 peak latency. The amplitude gradient of the NC group is steeper than that in the ASD group, which roughly corresponds to the statistically significant differences (Table 1). 